\title{
DECOMPOSIÇÃO DO FOLHEDO EM REFLORESTAMENTO CILIAR NA BACIA HIDROGRÁFICA DO RIO SÃO FRANCISCO, MINAS GERAIS
}

\author{
Flávia Peres Nunes ${ }^{1}$, Maria Tereza Cândido Pinto²
}

(recebido: 23 de janeiro de 2010; aceito: 28 de fevereiro de 2012)

\begin{abstract}
RESUMO: Neste trabalho, objetivou-se analisar a dinâmica da decomposição do folhedo em um reflorestamento ciliar no alto São Francisco, MG, de forma comparada a uma floresta ciliar nativa, para testar a hipótese de que a decomposição é dependente da estrutura e da composição florística da vegetação. A taxa de decomposição foi medida pela perda mensal de massa foliar armazenada em 12 "litterbags" de $20 \times 20 \mathrm{~cm}$, contendo 5 gramas de folhedo recém-caído e seco, distribuídos aleatoriamente nos dois trechos de vegetação e retirados mensalmente. A cinética da perda de massa foi mais rápida na mata nativa, com um $\mathrm{T}_{50 \%}$ em 5 meses após o início do experimento (02/2002), em detrimento do reflorestamento, cuja perda foi de somente $30 \%$ do valor inicial no período. Tal fato parece refletir a estrutura e composição em espécies dos trechos de vegetação e o clima local, uma vez que a mata nativa, cujo dossel é mais fechado, apresentou menor luminosidade, resultando em maior umidade e temperatura constantemente amena em seu interior, o que pode ter favorecido a proliferação de microorganismos decompositores, além da composição florística discrepante, uma vez que o reflorestamento apresentou menor diversidade de espécies, com o predomínio de Bauhinia variegata L., frente à maior diversidade da mata nativa. Além disso, o fragmento de mata ciliar nativo apresentou teores de matéria orgânica no folhedo maiores que no trecho reflorestado, o que pode ter contribuído para uma decomposição mais rápida.
\end{abstract}

Palavras-chave: Decomposição de serapilheira, mata ciliar, reflorestamento, bacia do rio São Francisco, recuperação de áreas degradadas.

\section{LITTER DECOMPOSITION IN A GALLERY FOREST REVEGETATION ON SÃO FRANCISCO RIVER BASIN, MINAS GERAIS STATE}

\begin{abstract}
This work analyzed the litter decomposition rates registered in riparian native and reforested forest fragments, to test the hypothesis that the decomposition is dependent on the structural and the floristic composition of the vegetation. The work was carried out in the upper São Francisco River Basin from September 2001 to August 2002. The decomposition rate was measured by quantifying the monthly mass loss of 12 litterbags $(20 \times 20 \mathrm{~cm})$ containing five grams of dry leaf in each one and located randomly in the two fragments analyzed. Mass loss kinetics was faster in the native forest, reaching the $T_{50 \%}$ in 5 months (02/2002) while loss in the reforested area was $30 \%$ during the same period. This could be reflecting the successional stage characteristic of each fragment and the local climate since the conditions at the native forest (close canopy, less luminosity, higher humidity and cooler constant temperatures) favor the proliferation of microorganisms. This can also be due to differences in floristic composition since the reforested area presents reduced species diversity, with a dominance of Bauhinia variegata L. In addition, the native riparian forest fragment presented higher levels of organic matter content which could contribute to accelerate the litter decomposition rates in this fragment.
\end{abstract}

Key words: Litterfall, gallery forest, reforestation, São Francisco river basin, rehabilitation of degraded areas.

\section{INTRODUÇÃO}

A drástica eliminação das matas ciliares e a fragmentação das florestas, verificada no Brasil e acelerada nas últimas décadas, têm causado um aumento significativo dos processos de erosão dos solos, com prejuízo à hidrologia regional, evidente redução da biodiversidade e a degradação de imensas áreas submetidas a essas ações antrópicas (BARBOSA, 2000). No estado de Minas Gerais, grande parte da vegetação ciliar foi eliminada em função de atividades antrópicas, o que dificulta a implementação de estratégias de conservação dos recursos hídricos, uma vez que para assegurar a manutenção da qualidade do ecossistema aquático é essencial a preocupação com o ecossistema ripário. Essa formação florestal é extremamente importante para a manutenção da qualidade ambiental dos rios, funcionando como filtro, retendo poluentes que seriam carreados para o curso d'água, afetando diretamente a quantidade e a qualidade da água e, consequentemente, a fauna aquática e os recursos pesqueiros (MARTINS, 2001). Embora a mata ciliar, em razão da sua localização e importância peculiares

'Bióloga, Professora Doutora em Ecologia - Universidade Federal de Minas Gerais - Instituto de Ciências Biológicas - Av. Antônio Carlos, 6627, Pampulha - Belo Horizonte, MG - flaviaperesnunes@yahoo.com.br

${ }^{2}$ Bacharel em História Natural, Professora Doutora em Ecologia e Recursos Naturais - Pontifícia Universidade Católica de Minas Gerais/PUC Minas Instituto de Ciências Biológicas e da Saúde - Avenida Com. José Gaspar, 500, Coração Eucarístico - Belo Horizonte, MG - agua@pucminas.br

Cerne, Lavras, v. 18, n. 3, p. 423-431, jul./set. 2012 
tenha papel fundamental na estruturação e dinâmica das áreas de contato entre os ambientes terrestres e aquáticos (NAIMAN; DECHAMPS, 1990; NAIMAN et al., 1989), continua a ser devastada, principalmente sob pressão da expansão agroindustrial, apesar de contar com proteção legal nos níveis federal e estadual (AIDAR; JOLY, 2003).

Atualmente, frente ao crescente ritmo da degradação ambiental, tem sido constatado um grande avanço na pesquisa científica e nos projetos de recuperação de matas ciliares (MARTINS, 2001). Entretanto, em vista da grave condição de preservação das matas ciliares, com o consequente comprometimento da qualidade ambiental das bacias hidrográficas, é urgente o desenvolvimento de modelos que visem não só à recuperação estrutural da vegetação ciliar, mas que considerem também a reabilitação de suas características eco-fisiológicas, especialmente relacionadas à ciclagem de nutrientes e matéria orgânica, por se tratar de um processo essencial na restauração e manutenção da fertilidade do solo, capazes de conferir maior estabilidade ao sistema (JORDAN; KLINGE, 1972). Dessa forma, o entendimento dos processos ecológicos que regulam a decomposição da serapilheira e a consequente ciclagem de nutrientes minerais e orgânicos é essencial para garantir o sucesso de reflorestamentos ciliares, pois a decomposição da serapilheira e a subsequente mineralização dos nutrientes, determinam fortemente o crescimento e as características de degradabilidade das espécies vegetais dominantes em um ecossistema (HOORENS et al., 2002). Entretanto, pouco se sabe sobre os processos ecológicos que regulam a ciclagem de nutrientes e minerais nesses ambientes, o que dificulta a implementação de estratégias para a recuperação das matas ciliares.

Embora a quantidade dos nutrientes fornecidos ao solo pela deposição de serapilheira sejam variáveis, sendo dependentes, principalmente, das espécies que compõem a formação florestal e da fertilidade do solo (BERTALOT et al., 2004), a serapilheira é a principal via de transferência de nutrientes (OLSON, 1963), como carbono, nitrogênio, fósforo e cálcio (COLE; RAPP, 1980), de forma que a manutenção da produtividade vegetal está intimamente relacionada ao equilíbrio do processo de ciclagem de nutrientes (POGGIANI, 1978). Além disso, a vegetação influencia as propriedades do solo, tanto de maneira direta, por meio do suprimento com matéria orgânica, quanto por um número de outras vias (DIAS et al., 2002). Reciprocamente, os solos exercem uma apreciável influência sobre o tipo de comunidade vegetal presente numa dada localidade (YOUNG, 1976), pois o acúmulo da serapilheira e o tempo de sua decomposição podem produzir mudanças radicais na estrutura das comunidades vegetais, afetando a substituição de espécies dominantes, bem como a riqueza e a diversidade da vegetação (BARBOSA, 2000).

A decomposição da serapilheira é regulada pelas condições do solo, fatores ambientais e pela qualidade do substrato (RESENDE, 2001), sendo que, em geral, observa-se um aumento da deposição da serapilheira até a idade em que as árvores atingem a maturidade ou fecham as suas copas (VITAL et al., 2004) e, após esse ponto, pode ocorrer ligeiro decréscimo ou estabilização da produção (BRAY; GHORAN, 1964). A degradabilidade da serapilheira é determinada pelas características edáficas do sítio, pela composição orgânica e nutricional do solo, pela natureza da comunidade decompositora, os macro e microrganismos (WERNECK et al., 2001), e pelas condições físico-químicas do ambiente, as quais são controladas pelas variáveis climáticas. De modo geral, o clima controla a decomposição em escala regional, pois as variáveis climáticas são os mais fortes determinantes dos níveis de perda de massa (DYER et al., 1990; VITOUSEK et al., 1994) e a composição química domina o processo em escala local (BERG, 1998), sendo que a qualidade do material vegetal exerce um importante papel no retorno de nutrientes ao solo (ABER et al., 1991; AUSTIN; VITOUSEK, 2000).

Dessa forma, a decomposição da serapilheira é a principal via de fornecimento de matéria orgânica e nutrientes em ecossistemas de florestas tropicais, onde os solos são muito úmidos e pobres em nutrientes, possibilitando que os elementos da biomassa vegetal entrem no sistema (MARTIUS et al., 2004). A importância de se avaliar os mecanismos de decomposição da serapilheira está na compreensão dos reservatórios e fluxos de nutrientes nos ecossistemas, os quais se constituem na principal via de fornecimento de nutrientes, por meio da mineralização dos restos vegetais, desempenhando importante papel na formação e manutenção da fertilidade do solo, bem como no fornecimento de nutrientes e matéria orgânica para a flora e fauna local (SOUZA; DAVIDE, 2001). Dessa forma, o estudo da decomposição da serapilheira e a ciclagem de nutrientes em ambientes ciliares, é fundamental para se conhecer a estrutura e o funcionamento de matas ciliares nativas e reflorestadas (CUNHA et al., 1993), visando ao estabelecimento de planos de recuperação de áreas degradadas. A decomposição da serapilheira não só regula

Cerne, Lavras, v. 18, n. 3, p. 423-431, jul./set. 2012 
a fertilidade do solo, mas é um dos fatores limitantes no estabelecimento e desenvolvimento de ecossistemas florestais, controlando a oferta de nutrientes orgânicos e minerais para a vegetação, sendo um dos principais processos ecológicos determinantes do sucesso de reflorestamentos ciliares.

Nesse contexto, o objetivo deste trabalho foi analisar a dinâmica da decomposição do folhedo em um reflorestamento ciliar, em comparação com um fragmento de mata ciliar nativa, no alto rio São Francisco, para testar a hipótese de que a decomposição da serapilheira é dependente da estrutura e da composição florística da vegetação.

\section{MATERIAL E MÉTODOS}

O presente trabalho foi desenvolvido em um trecho de reflorestamento ciliar de 3,0 ha, utilizando-se como testemunho para comparações um fragmento de mata ciliar nativa de 3,6 ha, distantes aproximadamente $30 \mathrm{~km}$, localizados no município de Lagoa da Prata, na região do alto São Francisco, em Minas Gerais (Figura 1).

O reflorestamento, localizado na margem direita do rio Santana $\left(20^{\circ} 05^{\prime} \mathrm{S}\right.$ e $\left.45^{\circ} 35^{\prime} \mathrm{W}\right)$, um importante tributário do rio São Francisco, foi implantado em substituição a canaviais anteriormente existentes, há 30 anos, aproximadamente. Foram utilizadas no plantio espécies provenientes de viveiros da região, na maioria não pertencentes às matas ciliares do rio São Francisco. $\mathrm{O}$ reflorestamento apresenta em relação às espécies arbóreas plantadas baixa diversidade $\left(H^{\prime}=2,37\right)$ e riqueza (17) específica, em conseqüência do predomínio de espécies como leucena (Leucaena leucocephala), amoreira (Morus nigra), santa-bárbara (Melia azedarach) e unha-de-vaca (Bauhinia variegata). Exemplares com 6 a $8 \mathrm{~m}$ de altura e $30 \mathrm{~cm}$ de circunferência à altura do peito (CAP), predominam no talhão, mas espécimes menores de $18 \mathrm{~m}$ de altura predominam no seu interior, originando um dossel baixo e com diversos pontos de clareiras (BARRETO, 2002).

O fragmento de mata ciliar nativa corresponde a

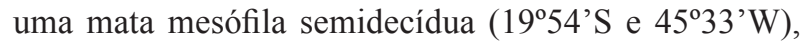
formada por um segmento florestal secundário em avançado estado de regeneração, entre grandes extensões de canaviais e pastagens. Espécies pioneiras são observadas em áreas de clareira no seu interior, mas a predominância é de exemplares característicos de estágio sucessional secundário ou clímax. Esse fragmento apresenta alta diversidade $\left(\mathrm{H}^{\prime}=2,71\right)$ e riqueza (26) específica de indivíduos arbóreos em relação ao reflorestamento, a composição de espécies em seu interior é característica de matas ciliares da região, como gameleira (Ficus gomeleira), pau-d'óleo (Copaifera langsdorfii), jatobá (Hymenaea coubaril) e vinhático (Platymenia foliolosa). O dossel, que atinge $30 \mathrm{~m}$ em média é uniforme, com raros pontos de clareira, onde surgem lianas e epífitas (BARRETO, 2002).

Ambos os trechos de vegetação ciliar localizam-se na planície de inundação na região do Alto São Francisco, no estado de Minas Gerais, com topografia rebaixada que acompanha a drenagem do rio, com formas aplainadas e superfícies onduladas da Depressão Sanfranciscana. Os solos predominantes, Latossolo Vermelho Escuro e Cambissolo, sustentam uma vegetação de cerrado, entremeada por grandes extensões de campo, mata capoeira (CETEC, 1983), pastagens, monocultura de cana-de-açúcar e, em menor extensão, por áreas cultivadas com gêneros alimentícios. Na região de Lagoa da Prata, o sistema fluvial é representado por um segmento meândrico do rio São Francisco e por inúmeras lagoas marginais situadas nos limites internos do município, além de diversos tributários, incluindo-se entre eles o rio Santana, um de seus importantes afluentes pela margem direita (CETEC, 1983).

A decomposição da serapilheira foi avaliada por meio da técnica dos "litterbags", onde as folhas são colocadas em bolsas de decomposição feitas de tela de nylon com $2 \mathrm{~mm}$ de malha, com dimensões de $20 \times 20 \mathrm{~cm}$ para permitir a entrada da mesofauna. Para tanto, foram colocados 12 litterbags em cada um dos 10 pontos amostrais demarcados no interior de cada um dos dois fragmentos de vegetação estudados, presos ao solo e cobertos com serapilheira, deixando-se espaço entre eles de $50 \mathrm{~cm}$. Os litterbags foram coletados mensalmente entre setembro/2001 e agosto/2002, colocados em sacos plásticos e levados ao laboratório onde foram abertos e as folhas limpas com um pincel fino a fim de retirar resíduos de solo e outros contaminantes (ANDERSON; INGRAM, 1996). Em seguida, as folhas foram colocadas em sacos de papel identificados e secas em estufa a $50^{\circ} \mathrm{C}$ e, após a estabilização do peso, colocados em dessecador e pesados para se determinar a perda de massa das folhas, obtidas à partir da obtenção do peso seco (REZENDE, 2001). De cada litterbag foi avaliada a perda de massa e a meia vida das folhas, $\left(\mathrm{T}_{(1 / 2)}\right)$, ou seja, em quanto tempo ocorreu a perda de $50 \%$ da massa inicial, determinada segundo: $\mathrm{T}_{(1 / 2)}=0,693 / \mathrm{k}$ (WESEMAEL, 1993). Também foram determinados os teores de cinza e matéria orgânica, através de alíquotas de

Cerne, Lavras, v. 18, n. 3, p. 423-431, jul./set. 2012 


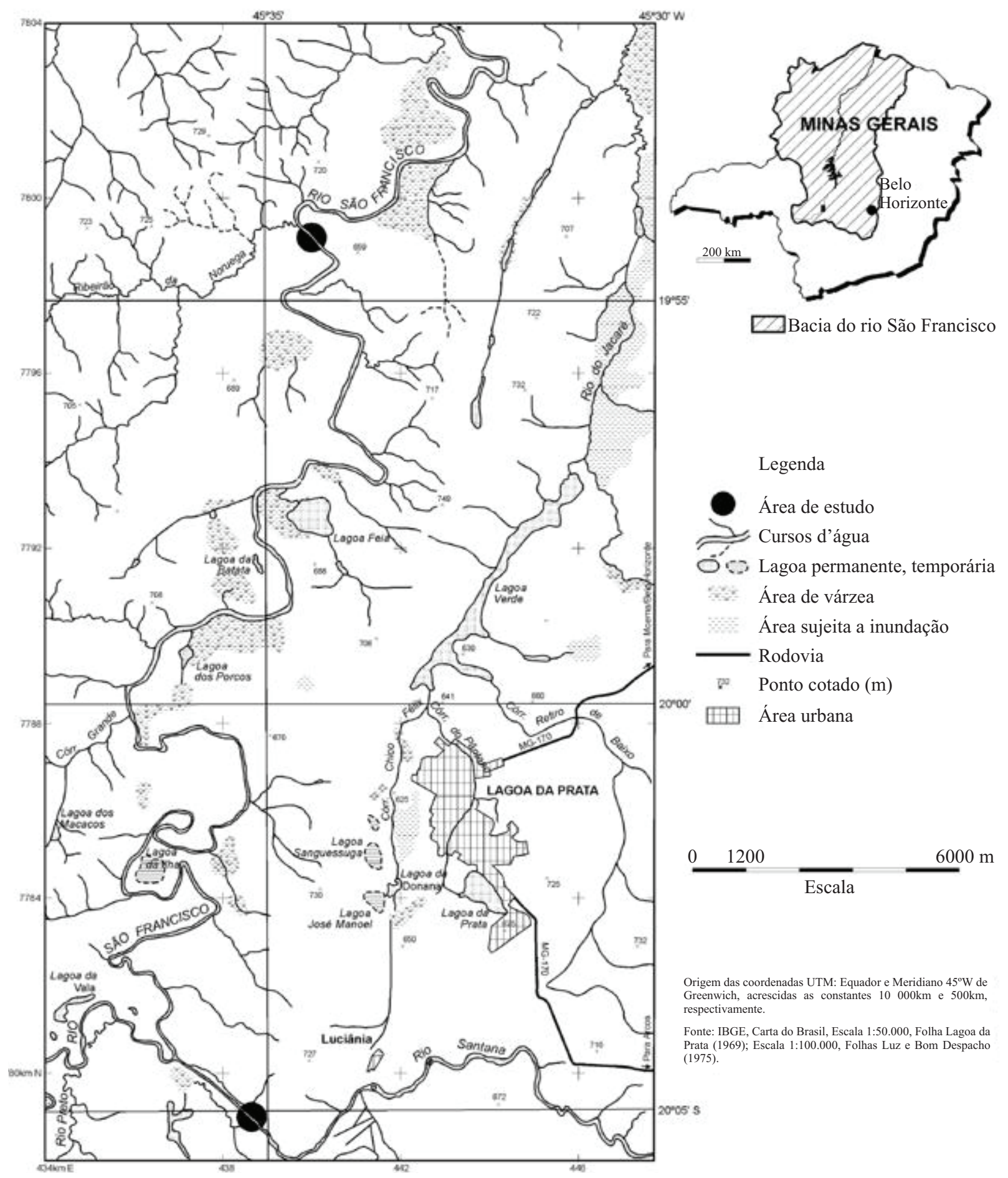

Figura 1 - Localização das áreas de estudo na porção alta da bacia hidrográfica do rio São Francisco, no município de Lagoa da Prata, estado de Minas Gerais, Brasil.

Figure 1 - Study areas on the São Francisco upper river basin, Minas Gerais State, Brazil.

Cerne, Lavras, v. 18, n. 3, p. 423-431, jul./set. 2012 
2 gramas de material seco e moído, incinerados em forno tipo mufla a $500^{\circ} \mathrm{C}$ (WESEMAEL, 1993).

A composição química do solo foi analisada por meio de amostras compostas coletadas até 20 centímetros de profundidade $(0-20 \mathrm{~cm})$, em períodos sazonais diferentes, na estação seca e úmida, em ambas as áreas de estudo (ANDERSON; INGRAM, 1996). Para a caracterização do clima local, classificado como tropical úmido, segundo Koppen, foram coletadas as médias das variáveis temperatura atmosférica, umidade relativa do ar e pluviosidade, medidas mensalmente no interior de cada área, por meio de termo-higrômetros e pluviômetros instalados no início do experimento.

Para se verificar a relação entre a perda de biomassa e o tempo nas duas áreas de estudo, utilizou-se a Análise de Regressão. Os resultados finais de biomassa remanescente foram submetidos ao teste de Tukey (ZAR, 1999), para se verificar a existência de diferenças significativas entre as áreas de estudo.

\section{RESULTADOS E DISCUSSÃO}

Os resultados de decomposição obtidos ao longo do estudo revelaram uma relação linear significativa $\left(F=0.453 ; p=0.504 ; y=0.68666+4.4322 ; R^{2}=0.009\right)$ entre a perda de biomassa e o tempo, tanto no reflorestamento $(\mathrm{R}=0,959)$ quanto na mata nativa $(\mathrm{R}=0,860)$. Embora a mata nativa tenha apresentado maior eficiência na degradação do folhedo em decomposição ao final do estudo, com 40,2\% da massa inicial, em detrimento do reflorestamento que apresentou $57,4 \%$ do folhedo inicial, não houve diferença significativa na decomposição entre as áreas $(p<0,05)$ (Figura 2).

A cinética da perda de massa foliar revelou maior velocidade na mata nativa, com $\mathrm{t}_{50 \%}$ registrado no mês de fevereiro/2002, indicando a perda de aproximadamente 2, $1 \mathrm{~g}(50 \%)$ da massa inicial, em 5 meses após o início do experimento, em detrimento do reflorestamento, cuja perda foi em torno de $1,5 \mathrm{~g}(30 \%)$ do valor inicial no mesmo período (Figura 2). A maior velocidade de decomposição na mata nativa parece refletir o estágio sucessional secundário desse fragmento de vegetação, composto por indivíduos arbóreos de grande porte, com a predominância de espécies secundárias e climáxicas, formando um dossel fechado (BARRETO, 2002), o que criou condições microclimáticas adequadas à decomposição, como menor penetração de luminosidade, ocasionando maior estabilidade climática, como revelado pela maior umidade atmosférica e temperatura mais baixa em relação ao

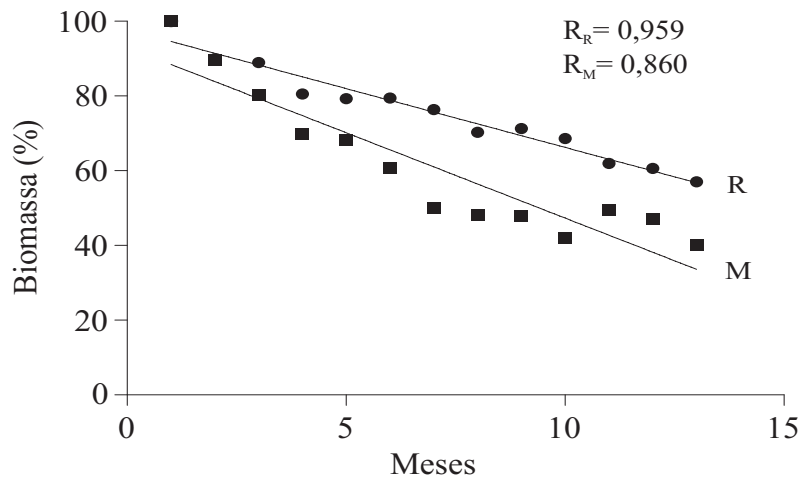

Figura 2 - Correlação entre a perda de biomassa do folhedo em decomposição e o tempo, nas áreas de reflorestamento (R) e mata ciliar nativa $(\mathrm{M})$.

Figure 2 - Correlation between litter biomass loss and time in reforestation area $(R)$ and in gallery forest $(M)$.

reflorestamento, cuja estrutura da vegetação resultou em um dossel mais aberto, permitindo grande incidência de radiação solar, contribuindo para o aumento da temperatura e diminuição da umidade (Tabela 1). Esse conjunto de características climáticas originaram um ambiente menos propício à proliferação de organismos decompositores (SWIFT et al., 1979), o que parece ter contribuído para a decomposição mais lenta observada no reflorestamento.

Tabela 1 - Variáveis climáticas das duas áreas de estudo: Reflorestamento (RE) e mata nativa (MN).

Table 1-Climatic factors in Reforestation of reforested area $(R)$ and Gallery forest $(M)$.

\begin{tabular}{lcccccc}
\hline \multirow{2}{*}{ Período } & \multicolumn{3}{c}{ Reflorestamento } & \multicolumn{3}{c}{ Mata nativa } \\
\cline { 2 - 7 } & $\begin{array}{c}\text { Temp } \\
\left({ }^{\circ} \mathrm{C}\right)\end{array}$ & $\begin{array}{c}\text { Um } \\
(\%)\end{array}$ & $\begin{array}{c}\text { Pluv } \\
(\mathrm{mm})\end{array}$ & $\begin{array}{c}\text { Temp } \\
\left({ }^{\circ} \mathrm{C}\right)\end{array}$ & $\begin{array}{c}\text { Um } \\
(\%)\end{array}$ & $\begin{array}{c}\text { Pluv } \\
(\mathrm{mm})\end{array}$ \\
\hline set/01 & 22,5 & 65 & 0,0 & 21,0 & 70 & 0,0 \\
out & 31,5 & 71 & 25,3 & 26,9 & 85 & 101,7 \\
nov & 30,7 & 89 & 225,8 & 26,4 & 96 & 307,5 \\
dez & 25,2 & 91 & 312,7 & 28,5 & 97 & 298,4 \\
jan/02 & 27,5 & 93 & 192,8 & 27,6 & 95 & 235,8 \\
fev & 21,0 & 95 & 306,5 & 21,0 & 98 & 300,8 \\
mar & 26,2 & 82 & 87,6 & 24,3 & 92 & 297,6 \\
mai & 21,8 & 71 & 32,1 & 21,8 & 83 & 107,4 \\
jun & 18,0 & 68 & 0,0 & 25,2 & 81 & 0,0 \\
jul & 24,0 & 60 & 0,0 & 20,0 & 78 & 17,6 \\
ago & 21,0 & 58 & 0,0 & 19,2 & 75 & 0,0 \\
\hline Média & 24,5 & 77 & 1182,8 & 23,8 & 86 & 1666,8 \\
\hline
\end{tabular}

Cerne, Lavras, v. 18, n. 3, p. 423-431, jul./set. 2012 
As variáveis climáticas avaliadas indicaram diferenças entre as áreas de estudo, o que pode estar relacionado com a dinâmica da decomposição da serapilheira, uma vez que a pluviosidade, umidade relativa do ar e temperatura estão entre os principais fatores reguladores da velocidade de degradabilidade do material vegetal sobre o solo. Apesar disso, apenas a umidade atmosférica foi correlacionada de forma significativa com a decomposição (Tuckey: $p<0.05$ ), o que não foi verificado em relação à temperatura e precipitação, Em se tratando de fragmentos de matas ciliares, os padrões de decomposição da serapilheira estão relacionados, sobretudo, aos teores de umidade, apresentando resultados diferentes mesmo estando essas matas situadas muito próximas entre si, sob o mesmo domínio climático (DURIGAM et al., 1995; PAGANO, 1989; VITAL et al., 2004), o que pode explicar os resultados diferentes encontrados para a mata ciliar nativa e o reflorestamento obtidos neste estudo. Além disso, a menor velocidade da decomposição do folhedo no reflorestamento, que é um plantio relativamente recente, pode ter refletido sua idade, uma vez que a idade das árvores pode influenciar significativamente na ciclagem de nutrientes (NEVES et al., 2001).

Em relação à composição do folhedo, os teores de matéria orgânica oscilaram entre $90 \%$ e $71 \%$ no reflorestamento e de $90 \%$ e $82 \%$ na mata nativa, no início e no final do período de estudos, respectivamente (Figura 3).

$\mathrm{O}$ maior teor de cinzas obtido no reflorestamento pode estar relacionado à ocorrência de queimadas anteriores ao experimento no local (LE SANN, 2002), de forma que o folhedo do experimento pode já ter sido parcialmente queimado ou contaminado pela grande quantidade de cinzas remanescente no solo, resultando em um menor retorno de matéria orgânica, em detrimento à mata ciliar nativa. Em contrapartida, tais queimadas podem, em parte, ter contribuído para uma maior liberação de nutrientes no solo, o que poderia ter influenciado nos altos teores de minerais observados no reflorestamento. Tal fato pode ser

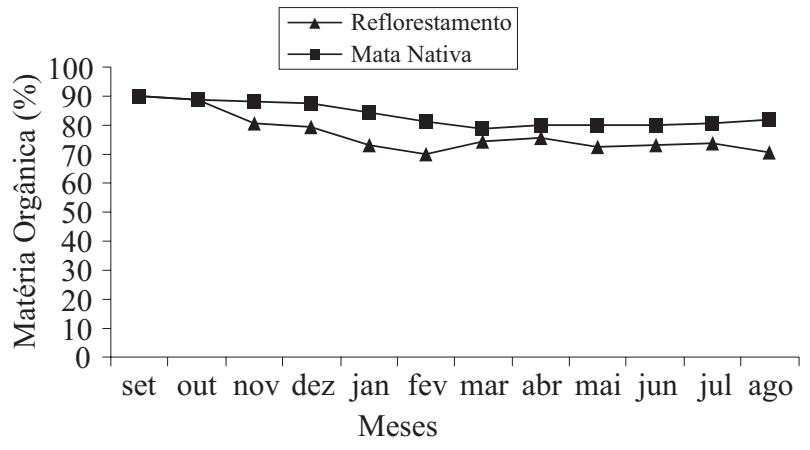

Figura 3 - Variação no teor de matéria orgânica do folhedo em decomposição no reflorestamento $(\mathrm{R})$ e na mata nativa $(\mathrm{M})$.

Figure 3 - Variation of litter organic matter content in reforestation area $(R)$ and in gallery forest $(M)$.

determinante no sucesso do reflorestamento, uma vez que a manutenção de matas mesófilas semidecíduas, como é o caso do fragmento nativo utilizado neste estudo, depende muito mais do retorno da matéria orgânica ao solo que de outros fatores (CESAR, 1993).

A velocidade da decomposição do folhedo está relacionada, principalmente, à constituição química do substrato (REZENDE, 2001), de forma que as diferenças encontradas para a dinâmica de decomposição no reflorestamento e na mata nativa parecem estar relacionadas às característica do solo nas áreas de estudo (Tabela 2).

As condições edáficas do reflorestamento e da mata nativa revelaram semelhanças na acidez, $\mathrm{pH}$, e fertilidade do solo, com altos teores minerais $(\mathrm{P}, \mathrm{Ke} \mathrm{Ca}) \mathrm{e}$ de matéria orgânica (MO), aproximando-se do observado em planícies aluviais do sudeste brasileiro (PINTO, 1992). Embora seja uma área degradada, com vegetação em início de sucessão ecológica, o reflorestamento apresentou valores de alguns nutrientes mais altos que a mata nativa, como $\mathrm{Na}$ e $\mathrm{Ca}$, o que pode ser explicado pelo histórico de cultivo da cana-de-açúcar no local, com adubações anuais ao longo de décadas que antecederam o plantio.

Tabela 2 - Nutrientes quantificados no substrato na área de Reflorestamento (RE) e na mata ciliar nativa (MN).

Table 2 - Nutrients concentrations of substratum in reforestation area (RE) and in gallery forest (MN).

\begin{tabular}{cccccccccccccc}
\hline Período & Área & $\begin{array}{c}\mathrm{pH} \\
\left(\mathrm{H}_{2} \mathrm{O}\right)\end{array}$ & $\begin{array}{c}\mathrm{P} \\
\left(\mathrm{mgdm}^{-3}\right)\end{array}$ & $\mathrm{K}$ & $\mathrm{Na}^{+}$ & $\mathrm{H}^{++} \mathrm{Al}^{+}$ & $\mathrm{Al}^{+}$ & $\mathrm{Ca}^{2}$ & $\mathrm{Mg}^{+2}$ & $\mathrm{SB}$ & $\mathrm{CTC}$ & $\begin{array}{c}\mathrm{V} \\
(\%)\end{array}$ & $\begin{array}{c}\mathrm{MO} \\
\left(\mathrm{kg}^{-1}\right)\end{array}$ \\
\hline \multirow{2}{*}{ set/01 } & $\mathrm{RE}$ & 6,1 & 5,72 & & 0,05 & 1,71 & 0,01 & 3,9 & 1,3 & 5,68 & 7,82 & 77,7 & 12,95 \\
& $\mathrm{MN}$ & 5,7 & 4,13 & 0,31 & 0,04 & 1,24 & 0 & 4,78 & 1,78 & 5,58 & 8,64 & 84,56 & 15,02 \\
\hline \multirow{2}{*}{ jan/02 } & $\mathrm{RE}$ & 6,8 & 5,98 & 0,53 & 0,06 & 1,6 & 0,02 & 3,52 & 0,96 & 5,56 & 6,76 & 75,14 & 14,77 \\
& $\mathrm{MN}$ & 6,3 & 4,22 & 0,38 & 0,05 & 1,4 & 0 & 4,96 & 1,65 & 5,97 & 8,99 & 83,92 & 16,85 \\
\hline
\end{tabular}

Cerne, Lavras, v. 18, n. 3, p. 423-431, jul./set. 2012 
Assim como o encontrado neste estudo, Toledo et al. (2002) evidenciam as diferenças na ciclagem de matéria orgânica entre áreas de florestas próximas em estados de sucessão ecológica distintos, de forma que a taxa de decomposição mais lenta observada no reflorestamento pode estar relacionada ao porte e diversidade dos exemplares. Além disso, a sua composição florística pouco diversificada pode ter contribuído para uma decomposição mais lenta com o predomínio de poucas espécies no seu interior, dentre as quais algumas exóticas com grande abundância, como a Bauhinia variegata $\mathrm{L}$., o que contribui para a baixa diversidade do material em decomposição, reduzindo, consequentemente, a diversidade da fauna que a utiliza. Bertalot et al. (2004) evidenciam uma maior retenção de nutrientes por leucenas, que indica uma decomposição do folhedo mais lenta em fragmentos de vegetação, onde há grande abundância dessa espécie, interferindo na dinâmica natural de ciclagem de nutrientes.

Os resultados obtidos para a dinâmica da decomposição e os teores de cinza e matéria orgânica do folhedo no reflorestamento parecem refletir, sobretudo, as condições climáticas da área, assim como a degradabilidade do material vegetal, determinado pela sua composição florística, em detrimento da mata nativa, que refletiu o padrão esperado para as matas ciliares nativas da região (VITAL et al., 2004), coincidindo com o encontrado em ambientes similares em áreas alagáveis no sudeste brasileiro (PINTO, 1992), embora a decomposição tenha se apresentado semelhante entre a mata nativa e o reflorestamento. Dessa forma, os resultados obtidos no presente trabalho demonstram a necessidade de se criar planos de recuperação de áreas ciliares degradadas que visem à reconstituição estrutural do ambiente, mas que considerem também a composição florística e as características eco-fisiológicas do local, priorizando espécies nativas, distribuídas de forma a simular a riqueza e diversidade florística das matas ciliares em ecossistemas tropicais.

\section{REFERÊNCIAS}

ABER, J. D.; MELILLO, J. M.; NADELHOFFER, K. J.; PASTOR, J.; BOONE, R. D. Factors controlling nitrogen cycling and nitrogen saturation in northern temperate forest ecosystems. Ecological Applications, Tempe, v. 1, p. 303$315,1991$.

AIDAR, M. P.; JOLY, C. A. Dinâmica da produção e decomposição da serapilheira do araribá (Centrolobium tomentosum Fuill. Ex Benth. - Fabaceae) em uma mata ciliar, rio Jacaré-Pepira, São Paulo. Revista Brasileira de Botânica, São Paulo, v. 26, n. 2, p. 193-202, 2003.

ANDERSON, J. D.; INGRAM, J. S. I. Tropical soil biology and fertility: a handbook of methods. $2^{\text {nd }}$ ed. Wallingford: CAB International, 1996.

AUSTIN, A. T.; VITOUSEK, P. M. Precipitation, decomposition in litter decomposability of Metrosideros polymorpha in native forests on Hawai. Journal of Ecology, Oxford, v. 88, p. 129-138, 2000.

BARBOSA, L. M. Considerações gerais e modelos de recuperação de formações ciliares. In: RODRIGUES, R. R.; LEITÃO-FILHO, H. F. (Ed.). Matas ciliares: conservação e recuperação. São Paulo: FAPESP, 2000.

\section{BARRETO, G. A avifauna como indicadora de qualidade} de reflorestamento ciliar no Alto São Francisco, MG. 2002. Dissertação (Mestrado em Zoologia) - Pontifícia Universidade Católica de Minas Gerais, Belo Horizonte, 2002.

BERG, B. Organic matter quality and $\mathrm{C} / \mathrm{N}$ ratio as controlling factors of RSOM turnover. Mittelung der Deutschen

Bodenkundlichen Gesellschaft, Stuttgart, v. 8, p. 87-79, 1998.

BERTALOT, M. J. A.; GUERRINI, I. A.; MENDOZA, E.; DUBOC, E.; BARREIROS, R. M.; CORREAA, F. M. Retorno de nutrientes ao solo via deposição de serapilheira de quatro espécies leguminosas arbóreas na região de Botucatu-São Paulo, Brasil. Scientia Florestalis, Piracicaba, v. 65, p. 219227, 2004.

BRAY, J. R.; GHORAN, E. Litter production in forest of the world. Advances Ecology of Research, Oxford, v. 2, p. 101157, 1964.

CESAR, O. Nutrientes minerais da serapilheira produzida na mata mesófila semidecídua da fazenda Barreiro Rico, município de Anhembi, SP. Revista Brasileira de Biologia, Rio de Janeiro, v. 53, n. 4, p. 659-669, 1993.

CETEC. Diagnóstico ambiental do estado de Minas Gerais. Belo Horizonte, 1983.

COLE, D.; RAPP, M. Elemental cycling in forested ecosystems. In: REICHE, D. E. (Ed.). Dynamic properties of forest ecosystems. Cambridge: Cambridge University, 1980.

Cerne, Lavras, v. 18, n. 3, p. 423-431, jul./set. 2012 
CUNHA, G. C.; GRENDENE, L. A.; DURLO, M. A.; BRESSAN, D. Nutrient cycling in a seasonal deciduous forest with special respect to the mineral content produced by the litterfall. Ciência Florestal, Santa Maria, v. 3, n. 1, p. 35-64, 1993.

DIAS, H. C. T.; FIGUEIRA, M. D.; SILVEIRA, V.; FONTES, M. L.; OLIVEIRA-FILHO, A. T.; SCOLFORO, J. A. R. S. Variação temporal de nutrientes na serapilheira de um fragmento de floresta estacional semidecidual montana em Lavras, MG. Cerne, Lavras, v. 8, n. 2, p. 1-16, 2002.

DURIGAN, G.; LEITÃO-FILHO, H. F.; PAGANO, S. N. Produção de serapilheira em matas ciliares na região oeste do Estado de São Paulo. Revista do Instituto Florestal, Piracicaba, v. 9, n. 1, p. 197-239, 1995.

DYER, M. L.; MEENTEMEYER, V.; BERG, B. Apparent controls of mass loss rate of leaf litter on a regional scale. Scandinavian Journal of forest Research, Stockholm, v. 5, p. 311-323, 1990.

HOORENS, B.; AERTS, R.; STROETENGA, M. Litter quality and interactive effects in litter mixtures: more negative interactions under elevated $\mathrm{CO}_{2}$ ? Journal of Ecology, Oxford, v. 90, p. 1009-1016, 2002.

JORDAN, C. F.; KLINGE, J. R. Mineral cycling: some basics concepts and their applications in a tropical rain forest. Ecology Systems, Palo Alto, v. 3, p. 33-50, 1972.

LE SANN, J. G. Atlas escolar de Lagoa da Prata. Belo Horizonte: UFMG, 2002.

MARTINS, S. V. Recuperação de matas ciliares. Viçosa, MG: Aprenda Fácil, 2001.

MARTIUS, C.; HÖFER, H.; GARCIA, M. V. B.; BÖMBKE, J.; HANAGARTH, W. Litter fall, litter stocks and decomposition rates in rainforest and agroforestry sites in central Amazonia. Nutrient Cycling in Agroecosystems, Dordrecht, v. 68, p. 137-154, 2004.

NAIMANN, R. J.; DECHAMPS, H. The ecology and management of aquatic-terrestrial ecotones. Paris: Parthenon, 1990. (Man and Biosphere Series).

NAIMANN, R. J.; DECHAMPS, H.; FOURNIER, F. Role of land/inland water ecotones in landscape management

Cerne, Lavras, v. 18, n. 3, p. 423-431, jul./set. 2012 and restoration: a proposal for collaborative research. Paris: UNESCO, 1989.

NEVES, E. J. M.; MARTINS, E. G.; REISSMANN, C. B. Deposição de serapilheira e de nutrientes em duas espécies da Amazônia. Boletim de Pesquisa Florestal, Colombo, v. 60, p. 43-47, 2001.

OLSON, J. S. Energy storage and the balance of producers and decomposers in ecological system. Ecology, Durham, v. 44, p. 322-331, 1963.

PAGANO, S. N. Produção de folhedo em mata mesófila semidecídua no município de Rio Claro, SP. Revista Brasileira de Biologia, Rio de Janeiro, v. 49, p. 633-639, 1989.

PINTO, M. T. C. Dinâmica de nutrientes na mata galeria da Lagoa do Diogo, Estação Ecológica de Jataí, Luís Antônio, SP. 1992. Tese (Doutorado) - Universidade Federal de São Carlos, São Carlos, 1992.

POGGIANI, F. Ciclo de nutrientes e produtividade de floresta implantada. Silvicultura, Rio de Janeiro, v. 1, n. 3, p. 45-48, 1978.

REZENDE, J. L. P. Decomposição de folhas de espécies arbóreas nativas de Mata Atlântica e de folhas de Eucalyptus urophylla em área de mata e de eucaliptal. 2001. Dissertação (Mestrado) - Universidade Federal de Minas Gerais, Belo Horizonte, 2001.

SOUZA, J. A.; DAVIDE, A. C. Deposição de serapilheira e nutrientes em uma mata não minerada e em plantações de bracatinga e de eucalipto em áreas de mineração de bauxita. Cerne, Lavras, v. 7, n. 1, p. 101-113, 2001.

SWIFT, M. J.; HEAL, O. W.; ANDERSON, J. M. Decomposition in terrestrial ecosystems. Berkeley: University of California, 1979.

TOLEDO, L. O.; PEREIRA, M. G.; MENEZES, C. E. G. Produção de serapilheira e transferência de nutrientes em florestas secundárias localizadas na região de Pinheiral, RJ. Scientia Forestalis, Piracicaba, v. 12, n. 2, p. 9-16, 2002.

VITAL, A. R. T.; GUERRINI, I. A.; FRANKEN, W. K.; FONSECA, R. C. B. Produção de serapilheira e ciclagem de nutrientes de uma floresta estacional semidecidual em zona ripária. Revista Árvore, Viçosa, v. 28, n. 6, p. 793-800, nov./dez. 2004. 
VITOUSEK, P. M.; TURNER, D. R.; PARTON, W. J.; SANFORD, R. L. Litter decomposition on the Mauna Loa Matrix: patterns, mechanisms and models. Ecology, Durham, v. 75, p. 418-429, 1994.

WERNECK, M. S.; PEDRALLI, G.; GIESEKE, L. F. Produção de serapilheira em três trechos de uma floresta semidecídua com diferentes graus de perturbação na Estação Ecológica do Tripuí, Ouro Preto, MG. Revista Brasileira de Botânica, São Paulo, v. 24, n. 2, p. 195-198, 2001.
WESEMAEL, B. V. Litter decomposition and nutrient distribution in humus profiles in some Mediterranean forests in southern Tuscany. Forest Ecology and Manegement, Amsterdam, v. 57, p. 99-114, 1993.

YOUNG, A. Tropical soils and soil survey. Cambridge: Cambridge University, 1976.

ZAR, J. H. Bioestatistical analysis. New Jersey: Prentice Hall, 1999.

Cerne, Lavras, v. 18, n. 3, p. 423-431, jul./set. 2012 
